\title{
Porquê seguir essa teoria?
}

A TEORIA DAS TEORIAS E A SEGUINTE: uma teoria será aceite por uma comunidade científica se explicar de melhor forma (ou mais extensamente) aquilo que se sabe, se estiver no limite daquilo que é conhecido sobre as outras partes do nosso universo e se fizer previsões verificáveis e, de preferência, arriscadas.

Às vezes, é mesmo assim. De facto, a teoria que fez o meu nome (e acrescentou à grandeza já reconhecida do homem com quem colaborei, o maior químico de síntese do século XX, Robert B. Woodward) elucidou muitas observações incongruentes e enigmáticas da química orgânica. E o "controle de simetria orbital", tal como o nosso complexo de ideias ficou conhecido, fez algumas previsōes arriscadas. Lembro-me nitidamente do dia em que Jerry Berson nos mandou os seus famosos resultados experimentais sobre a estereoquímica da reacção sigmatrópica $[1,3]$. Devia se comportar de uma certa maneira, deduziu ele da nossa teoria uma aproximação não-intuitiva. E assim foi.

No entanto, muito do que faz com que se aceitem as teorias tem pouco a ver com a racionalização e a previsão. Sustento que, em vez disso, o que importa é uma impressionante série de factores em que as atitudes psicológicas têm uma componente proeminente.

\section{Simplicidade}

Uma equação simples que descreve um fenómeno físico (ou, melhor, muitos), a molécula com a forma de um sólido platónico com geometria regular, o mecanismo simples $(A \rightarrow B$, num só passo) são esteticamente extremamente apelativos, atingem a nossa alma directamente. São maravilhosamente simples e simplesmente maravilhosos. Teorias deste tipo são espantosas no sentido literal da palavra - quem o pode negar da teoria da evolução, da equação de Dirac, ou da relatividade geral?

Convém ter um pouco de cautela e ponderar o facto que a propaganda política apela de uma forma flagrante à nossa predilecção psico-biológica para a simplicidade. Será o mundo simples? Ou será que apenas queriamos que fosse assim? Nos sonhos de alguns, a beleza e a simplicidade das equações tornam-se num critério da sua veracidade. As teorias simples parecem validar o sacrossanto Ockham's razor. Eu próprio sucumbi e prediquei a concisão poética e generalidade das explicações orbitais.

Para corrigir esta propensão dos cientistas para a simplicidade, podíamos perguntar-Ihes o que consideram ser belo nas artes, seja na música ou nas artes visuais. Preferem as Variações Goldberg de Bach ou uma música para dançar cujo tema é repetido dez vezes seguidas de forma idêntica? Alguma vez um animal foi pintado para mostrar a sua simetria bilateral?
Apesar disso, não há saída; uma teoria simples mas que explica muito é geralmente aceite num abrir e fechar de olhos.

\section{Contar uma história}

E se o mundo fosse complexo? Aqui, quebra-se a simetria; ali, a reacção química aparentemente mais simples, combustão do hidrogénio com formação de água, obedece a um mecanismo complicado. A maneira através da qual uma sub-unidade de hemoglobina comunica a sua oxigenação a uma segunda sub-unidade, uma tarefa essencial, tem a sofisticação de uma banda desenhada de Rube Goldberg. Só para não mencionar a complexidade de qualquer resposta biológica, do aumento da pressão sanguínea ou da descarga de adrenalina quando uma cobra nos ataca, até ao retorno de um serviço de pingue-pongue cortado. A teoria de Max Perutz sobre a cooperatividade da associação do oxigénio à hemoglobina, a forma como os ribossomas funcionam - estas exigem explicações complicadas. E sim, foi o tactear inerente da evolução que as tornou complexas. Mas as reacções químicas mais simples - uma vela a arder - também são intrincadas. Tão complexas como a física essencial da maleabilidade, brilho e dureza dos metais. Ou a geologia dos sopros hidrotérmicos.

Quando as coisas são complexas mas compreensíveis, os homens fabricam histórias. Fazemo-lo por várias razões: $A \rightarrow B$ não precisa de história. Mas $\mathrm{A} \rightarrow \mathrm{B} \rightarrow \mathrm{C} \rightarrow \mathrm{D}$ e não $\mathrm{A} \rightarrow \mathrm{B} \rightarrow \mathrm{C}^{\prime} \rightarrow \mathrm{D}$ é já

\footnotetext{
* Tradução: Gabinete de Tradução da Universidade Católica Portuguesa, Revisão: L. G. Arnaut, Departamento de Quimica, Universidade de Coimbra.
} 
uma história em si. 0 psicólogo Jerôme Bruner escreveu, "Para que haja uma história, algo inesperado tem de acontecer". Na ciência, o inesperado aguarda-nos na próxima esquina experimental. As histórias "domesticam o inesperado," na formulação de Bruner.

Contar histórias parece estar enraizado na nossa psique. Iria mesmo dizer que com a nossa aptidão para falar e escrever, esta é a nossa maneira de extrair prazer, psicológico, de um mundo caótico. Os cientistas não são uma excepção. Parte da história que nos contam narra como lá chegaram - os filmes raios $X$ medidos ao longo de uma década, os becos sem saída e as pistas falsas de síntese química. Nunca é simples, e a serendipidade substituiu aquilo que antigamente se chamava a Graça de Deus. No final, acabamos por triunfar. É tentador, e nada disso diminui a ingenuidade do acto criador.

Pensando nas teorias, a narração de histórias tem alguns aspectos particulares. Há sempre um princípio para uma teoria - modelar assunções, talvez dar conta de observações inesperadas. Depois, numa teoria conduzida pela matemática, segue-se uma espécie de estágio de desenvolvimento. Tenta-se uma coisa: não leva a lado nenhum, ou deixa um sentimento de insatisfação. Por isso tenta-se uma variação sobre o que era um tema menor, e - de repente - eleva-se. A resolução e a finalização seguem-se. Penso na surpresa que se tem quando se faz uma transformada de Fourier, ou quando se vêm os valores próprios aparecer apenas de uma equação e condições fronteira.

É triste mas, nos registos escritos das teorias, muita da narrativa da luta pelo conhecimento é omitida, por causa da auto-censura e do desejo de nos mostrarmos mais racionais do que somos. Está bem; felizmente que ainda podemos ver secções do desenvolvimento da sinfonia teórica quando examinamos um conjunto de teorias, criadas por muitas pessoas, não apenas uma, vagueando na procura do conhecimento.

O outro local onde prevalece a narrativa é na etapa de formulação de hipóteses científicas. É aqui que "o alcance da imaginação" da ciência, como the chamou Jakob Bronowski, é explícito. Dentro em pouco será trazido de volta à terra pela experimentação, mas aqui o homem audaz pode levantar voo, imaginar qualquer esquema louco. $E$, da forma como funciona a ciência, se ficar demasiado cego pelo seu próprio preconceito para ver as falhas das suas fantasias teóricas, é certo que os outros as verão.

Muitas teorias são populares porque contam uma história entusiástica, que reflecte a forma como funciona o mundo, e que pode ser arquivada para lidar com a próxima dificuldade. As histórias podem ser divertidas: poderá haver teorias com sentido de humor?

\section{Uma Mala de Viagem}

As teorias que procuram ser aceites é melhor serem portáveis. Claro, as pessoas aceitarão um ritual iniciático, um manual duro-de-roer para aprenderem a dominar a teoria. Mas se todas as aplicações da teoria exigirem uma consulta ao seu formulador (este é o objectivo da comercialização, a antitese da ética da ciência), a teoria será rapidamente abandonada. As teorias mais populares são as que podem ser aplicadas por outros para obter resultados surpreendentes. O formulador da teoria teria dado um braço para o ter feito primeiro, mas os amigos deveriam refreá-lo - é melhor se outro o fizer. E o citar.

Modelos relativamente simples que admitem uma solução analítica têm um papel especial na aceitação e popularidade das teorias junto dos outros teóricos. Estou a pensar no oscilador harmónico, nos Hamiltonianos de Heisenberg e de Hückel, o modelo de Ising, ou as minhas próprias interacções de orbitais. Os modelos tornam-se módulos de uma construção teórica, aplicando-se a qualquer problema como primeiro (mas não último) recurso. Por um lado isto é uma moda, por outro lado é um testemunho da nossa predilecção pela simplicidade. Mas, mais significativo ainda, a utilização de modelos solúveis transmite confiança no valor da metáfora - junta-se uma prova experimental a outras. É também demonstrativo do desejo existencial de tentar alguma coisa - vamos tentar isto.

\section{Produtividade}

As melhores teorias são produtivas, pois estimulam a experimentação. A ciência é uma forma interactiva maravilhosa de adquirir conhecimento fiável. Quanta excitação existe numa pessoa $A$ que propõe uma visão de como funcionam as coisas, que é testada por B, usada por $C$ para motivar a síntese de uma molécula que testa os limites da teoria, que leva D (não C) a descobrir que a molécula é um supercondutor ou um agente anti-tumor, originado uma chusma de estudantes de doutoramento a fazer pequenas modificações na molécula ou procedimentos! As pessoas precisam de razões para fazerem as coisas. As teorias dão essas razões, certamente para testar as teorias (e com maior prazer se provarem que as teorias estão erradas), mas também para terem uma razão para fazerem a molécula seguinte. As teorias que provocam experiências são verdadeiramente apreciadas por uma comunidade que em todas as ciências, mesmo na Física, é fundamentalmente experimentalista.

Um "corolário" do significado da produtividade é que as teorias que são fundamentalmente insustentáveis ou mal definidas, podem ainda assim ser imensamente produtivas. Assim foi com o flogisto nos seus dias, assim foi na Química com a ideia das energias de ressonância calculadas com o modelo de Hückel. As pessoas fizerem esforços tremendos para sintetizarem moléculas que nunca teriam feito (e descobriram muita química fascinante nesse processo) com base em "energias de ressonância" que tinham pouca relação com a estabilidade, termodinâmica ou cinética. Teve alguma importância que Colombo se tenha enganado, na proposta do seu "projecto de investigaçāo", na distância a que estava a Índia?

Nas palavras de Jerry Berson, "Muita da ciência consiste em factos experimen- 
tais permanentes obtidos em testes de teorias temporárias".

\section{Quadros para a Compreensão}

Stephen G. Brush estudou recentemente uma variedade de domínios e de descobertas, para averiguar qual o papel que as previsões têm na aceitação das teorias. Eis o que ele tem a dizer sobre a nova mecânica quântica: "As novas previsões não tiveram praticamente nenhum papel na aceitação da teoria física mais importante do século XX, a mecânica quântica. Os físicos rapidamente aceitaram essa teoria porque proporcionava uma descrição dedutiva coerente de uma grande gama de factos empíricos conhecidos..." Muitas teorias fazem relativamente poucas previsões (a mecânica quântica acabou por fazer algumas) mas mesmo assim são aceites porque têm um poder explicativo tremendo. Fazem-no através de uma classificaçāo, proporcionando um quadro (para a mente) que ordena uma imensa quantidade de observações. É isto que eu penso que fizeram as teorias sobre acidez e basicidade (à la Lewis ou Brønsted) do século XX. Alternativamente, a compreensão oferecida é a do mecanismo - esta é a força da teoria da evolução.

É melhor distinguir os conceitos de teoria, explicação e compreensão. Ou pelo menos tentar fazê-lo pois eles resistem à sua diferenciação. Evelyn Fox Keller, no seu recente e brilhante livro, Making Sense of Life, tem muitas fábulas instrutivas sobre a aceitação das teorias e diz o seguinte sobre a explicação:

"Uma descrição ou um fenómeno conta como uma explicaçẫo .... se e só se preenche as necessidades de um individuo ou de uma comunidade. 0 desafio, portanto, está na compreensão das necessidades que os diferentes tipos de explicação satisfazem. As necessidades, claro está, variam, e variam inevitavelmente: variam não só com o estado da ciência num tempo determinado, com a tecnologia local, com as oportunidades sociais e económicas, mas também com preocupações culturais mais alargadas"
Tal como Bas van Fraassen argumentou incisivamente, qualquer explicação é uma resposta. Se aceitarmos isso, a natureza da questão torna-se essencial, assim como a nossa recepção da resposta. Tanto a questão reconstituída do "porquê?" como a nossa resposta são dependentes do contexto e subjectivas. Compreender, diz van Fraassen, "consiste em estar numa posição de poder explicar." E assim é a subjectividade de um universo pragmático.

A propósito, as explicaçōes são quase sempre histórias. De facto, são histórias moralistas e determinísticas. Pois, para haver satisfação, não basta dizer $A \rightarrow B \rightarrow C \rightarrow D$, mas $\operatorname{sim} A \rightarrow B \rightarrow C \rightarrow D$ porque $\mathrm{A}, \mathrm{B}$ e $\mathrm{C}$ têm estas e aquelas propriedades. A forte convicção da casualidade aqui implícita, justificada por uma razão aparentemente irrefutável, pode ser perigosamente inebriante. Esta é uma das razões pelas quais eu não gostaria de ver os cientistas e os engenheiros a governarem o mundo.

A aceitação das teorias depende tanto da psicologia dos seres humanos como do conteúdo das teorias. São os seres humanos que decidem, individualmente ou enquanto comunidade, se uma teoria tem de facto um poder explicativo ou oferece uma compreensão. É por isso que factores aparentemente "extracientíficos" como a produtividade, portabilidade, poder de narração e estética, também contam. Às vezes a aceitação demora muito tempo (testemunhado pela deriva dos continentes), mas às vezes é imediata e intuitiva - fica bem. É como uma bela camisola.

\section{É uma Prenda}

Há mais qualquer coisa, ainda mais fundamental do ponto de vista psicológico, a funcionar. Todas as sociedades usam prendas, como ofertas altruístas mas, mais importante ainda, como meio de mediação nas interacções sociais. Na ciência a prenda é tanto transparente como central. A ciência pura é a forma mais próxima de uma economia de prendas, tal como argumentou Jeffrey Kovac. Cada artigo da literatura científica é uma prenda para todos nós. Cada método analítico, cada instrumento. Claro que se deseja que a prenda seja bonita (como o são as prendas simples, mas também aquelas que trazem uma boa história consigo). Mas que a oferta seja útil (portável, produtiva) confere-lhe um valor especial. Quem deu a prenda será lembrado, a cada momento, por aquele que a recebeu.

O propósito da teoria, escreve Berson, é "trazer ordem, clareza e previsibilidade a um pequeno canto do mundo". Isso chega. Uma teoria é, então, uma prenda especial, uma prenda para a mente numa sociedade (científica, e não o mundo) onde o pensamento e a compreensão são dominantes. Uma prenda de um ser humano para o outro, para nós todos.

\section{Agradecimentos}

Quero agradecer a Michael Weisberg pelos seus comentários e questões incisivas.

\section{Bibliografia}

Berson, J. A.. 1999. Chemical Creativity: Ideas from the Work of Woodward, Hückel, Meerwein, and Others, Weinheim, Germany: Wiley-VCH.

Bruner, J. 2002. Making Stories. New York: Farrar, Strauss and Giroux.

Brush, S. G. 1994. Dynamics of Theory Change: The Role of Predictions. In Proceedings of the 1994 Biennial Meeting of the Philosophy of Science Association, 2: 133 145, ed. D. Hull et al. East Lansing, Mich.: PSA.

Hoffmann, R., V. I. Minkin and B. K. Carpenter. 1996. Ockham's razor and chemistry. Bulletin de la Societé Chimique de France 133: 117-130.

Keller, E. F. 2002. Gifts and commodities in science. Hyle 7: 141-153.

Van Fraassen, B. C. 1980. The Scientific Image. Oxford: Clarendon Press, pp. 132157.

Originalmente Publicado em American Scientist, Janeiro/Fevereiro 2003, pp.9-11, a revista de Sigma Xi, The Scientific Research Society. Direitos de reprodução gentilmente cedidos à Sociedade Portuguesa de Química. 